総 説

\title{
粉末焼結の有限要素シミュレーション
}

\author{
森 謙一郎 \\ 豊橋技術科学大学生産システム工学系, $テ 441-8580$ 愛知県豊橋市天伯町雲雀ヶ丘 1-1.
}

\section{Finite Element Simulation of Powder Sintering}

\begin{abstract}
Ken-ichiro Mori
Dept. Production Systems Eng., Toyohashi University of Tech., 1-1 Hibarigaoka, Tempaku-cho, Toyohashi 441-8580, Japan.
\end{abstract}

Received June 30, 2009

\section{SYNOPSIS}

A viscoplastic finite element method for simulating powder sintering processes was presented. This method was formulated on the basis of the plasticity theory of a porous material to take the change in apparent volume during the sintering into consideration. To simulate non-uniform shrinkage in the sintering, the shrinkage strainrate was included in the formulation. In addition, both microscopic and macroscopic shrinkages in the sintering were simulated by coupling the finite element method with the Monte Carlo method. The calculated results in sintering processes were shown.

KEY WORDS

sintering, powder forming, finite element method, compaction, Monte Carlo method

\section{1 緒 言}

粉末成形品は金属またはセラミックス粉末を圧粉成形した 後, 焼結によって製品になる。焼結では粉末粒子を拡散接合 させて製品とするが, 粉末粒子間にある隙間が小さくなって 収縮し, 圧粉体が不均一な密度分布を有していると焼結時に 不均一に収縮する．また，大きな製品では自重によって不均 一に収縮したり, 焼結時の温度分布, 底部の摩擦などによっ ても不均一収縮が現れる. 不均一に収縮すると, 所定の製品 形状から外れて製品欠陥になる.

有限要素法が塑性加工のような生産加工に応用されて, そ の有用性が認識されるようになってきた，有限要素法は，素 材を多数の要素に分割して計算する方法であり, 実際的な境 界条件および材料特性が考慮でき，しかも自由度が大きいた め精度の高い計算結果が得られる. 有限要素法の精度が向上 したため, 実験による試行錯誤に代ってシミュレーションが 用いられるようになってきている. 粉末成形にも有限要素法 は応用されており, 圧粉成形, 焼結, 焼結金属の加工などが シミュレーションされている ${ }^{1-3)}$.

本解説では, 圧粉体の焼結収縮における変形挙動をシミュ レーションする有限要素法について説明する.

\section{2 焼結収縮の有限要素法}

圧粉体は焼結されるが, 圧粉体の体積は焼結時に変化する ことが知られている.特にセラミックス材では, 数 $10 \%$ 収縮 し, 寸法精度が問題となっている. 圧粉成形では, 工具の形 状および摩擦によって圧粉体に密度の分布を生じるが, 圧粉 体に密度分布があると焼結時に不均一に収縮する. また, 自 重, 敷板との摩擦などによっても不均一収縮が起こる. 密度 分布を有する圧粉体は焼結中に不均一に収縮し, その不均一 収縮によって素材に塑性変形が生じる.すなわち, 密度分布 のない圧粉体では均一に収縮して塑性変形はないが, 密度分 布を有する圧粉体では素材内部で体積収縮率が分布し体積収 縮率の差によって素材内部に塑性変形が生じる.このため密 度分布を有する圧粉体では, 焼結後の形状は圧粉体の形状と 相似形にはならない。

焼結中の圧粉体は多孔質体であるため, 塑性変形において は次の多孔質体の降伏条件に従うものとする ${ }^{4}$.

$$
\begin{aligned}
\left(\rho^{n} \bar{\sigma}\right)^{2}=\frac{1}{2}\left\{\left(\sigma_{x}-\sigma_{y}\right)^{2}\right. & +\left(\sigma_{y}-\sigma_{z}\right)^{2}+\left(\sigma_{z}-\sigma_{x}\right)^{2} \\
& \left.+6\left(\tau_{x y}^{2}+\tau_{y z}^{2}+\tau_{z x}^{2}\right)\right\}+\left(\frac{\sigma_{m}}{f}\right)^{2}
\end{aligned}
$$




$$
\mathrm{f}=1 / \mathrm{a}(1-\rho)^{\mathrm{m}}
$$

ここで, $\sigma_{\mathrm{m}}$ は静水圧応力, $\rho$ は相対密度 (圧粉体の密度/粉末 の密度), $\bar{\sigma}$ は相当応力, $n, a, m$ は材料定数である, 素材の質 量は変化しないため, 密度変化として取り込んでいる. 式(1) を塑性ポテンシャルとして法線則を適用すると, 粘塑性多孔 質材料に対する応力の各成分が得られる.

$$
\begin{aligned}
& \{\sigma\}=[\mathrm{D}]\{\dot{\varepsilon}\} \\
& {[\mathrm{D}]=\frac{\rho^{2 \mathrm{n}-1} \bar{\sigma}}{\dot{\bar{\varepsilon}}}\left[\begin{array}{ccccccc}
\mathrm{b} & \mathrm{c} & \mathrm{c} & 0 & 0 & 0 \\
\mathrm{c} & \mathrm{b} & \mathrm{c} & 0 & 0 & 0 \\
\mathrm{c} & \mathrm{c} & \mathrm{b} & 0 & 0 & 0 \\
0 & 0 & 0 & \mathrm{~d} & 0 & 0 \\
0 & 0 & 0 & 0 & \mathrm{~d} & 0 \\
0 & 0 & 0 & 0 & 0 & \mathrm{~d}
\end{array}\right]} \\
& \mathrm{b}=\mathrm{f}^{2}+\frac{4}{9}, \quad \mathrm{c}=\mathrm{f}^{2}-\frac{2}{9}, \quad \mathrm{~d}=\frac{1}{3}
\end{aligned}
$$

この材料では, 相当ひずみ速度㐫は次式で表され, 密度変化, すなわち体積変化を生じるために体積ひずみ速度の項を含ん でいる.

$$
\begin{aligned}
\dot{\bar{\varepsilon}}^{2}=\rho^{2 n-2}\left\{\frac{2}{9}\left(\dot{\varepsilon}_{x}-\dot{\varepsilon}_{y}\right)^{2}+\right. & \left(\dot{\varepsilon}_{y}-\dot{\varepsilon}_{z}\right)^{2}+\left(\dot{\varepsilon}_{z}-\dot{\varepsilon}_{x}\right)^{2} \\
& \left.+\frac{3}{2}\left(\dot{\gamma}_{x y}^{2}+\dot{\gamma}_{y z}^{2}+\dot{\gamma}_{z x}^{2}\right)\right\}+\left(f \dot{\varepsilon}_{v}\right)^{2}
\end{aligned}
$$

多孔質材料では圧縮性を示すため, ひずみ速度から直接応力 が計算できる.多孔質材料の密度は塑性変形によって変化し, その密度変化は各変形ステップの体積ひずみ増分 $\Delta \varepsilon_{v}$ から計 算できる.

$$
\rho_{1}=\rho_{0} \exp \left(-\Delta \varepsilon_{v}\right)
$$

ここで, $\rho_{0}, \rho_{1}$ は各変形ステップの最初および最後の相対密 度である。

不均一収縮は焼結後の形状予測を困難にするため, 焼結時の 不均一収縮をシミュレーションする方法が提案されている5). 全ひずみ速度 $\dot{\varepsilon}_{\mathrm{ij}}^{\mathrm{t}}$ は焼結収縮のひずみ速度 $\dot{\varepsilon}_{\mathrm{ij}}^{\mathrm{s}}$ と塑性変形の ひずみ速度 $\dot{\varepsilon}_{\mathrm{ij}}$ の和となる.

$$
\dot{\varepsilon}_{\mathrm{ij}}^{\mathrm{i}}=\dot{\varepsilon}_{\mathrm{ij}}^{\mathrm{s}}+\dot{\varepsilon}_{\mathrm{ij}}
$$

有限要素法では, 各要素内のひずみ速度は節点速度の 1 次式 で表される。

$$
\{\dot{\varepsilon}\}=[B]\{v\}
$$

ここで，[B] は座標から得られるマトリックスである．式 (5) と式(6)を式(2)に代入すると, 応力は次式で表わされる.

$$
\{\sigma\}=[\mathrm{D}][\mathrm{B}]\left\{\mathrm{v}_{\mathrm{e}}\right\}-[\mathrm{D}]\left\{\dot{\varepsilon}^{\mathrm{s}}\right\}
$$

大きな圧粉体の焼結では, 自重の影響によっても素材は塑 性変形し, 有限要素法における節点力は自重の影響を取达ん で次式で表される。

$$
\{\mathrm{P}\}=\int_{\mathrm{V}}[\mathrm{B}]^{\mathrm{T}}\{\sigma\} \mathrm{dV}+\int_{\mathrm{V}} \mathrm{g} \rho \gamma[\mathrm{N}] \mathrm{dV}
$$

ここで, $\mathrm{g}$ は重力加速度, $\gamma$ は密度, $\{\mathrm{N}\}$ は要素の形状関数で ある. 式 (8)の節点力に式(7)の応力を代入すると, 節点力は 次のよう表わされる.

$$
\begin{aligned}
\{P\}=\int_{V}[B]^{T}[D][B] d V\left\{v_{e}\right\} & \\
& -\int_{V}[B]^{T}[D]\left\{\dot{\varepsilon}^{s}\right\} d V+\int_{V} g \rho \gamma[N] d V
\end{aligned}
$$

上式の右辺第 1 項は全ひずみ速度, 第2 項は焼結収縮, 第 3 項 は自重の影響をそれぞれ表している．式(9)の節点力を次の ように節点ごと釣合わせ，得られた連立方程式を解くことに よって解が求まる.

$$
\sum^{\text {element }} \mathrm{P}_{1}=\left\{\begin{array}{l}
0 \text { (in material) } \\
\left.\mathrm{F}_{1} \text { (on surface) }\right)
\end{array},\right.
$$

ここで, $F_{i}$ は節点に働く摩擦である. 式(9)で表わされる $\left\{\dot{\varepsilon}^{s}\right\}$ は実験より求められる材料定数であり, 本定式化は収縮ひず み速度を材料定数として与える粘塑性有限要素法の定式化で あり，焼結では温度上昇に伴って素材は収縮するが，それを 体積ひずみ速度に置き換えている，焼結は高温で行われ，素 材のひずみ速度依存性は大きくなり，粘塑性材料としてひず み速度依存性を取り込んでいる。

\section{3 焼結後の形状予測}

セラミックス材は構造用材料としても多く用いられている ため, 製品の寸法精度が重要になる. セラミックス材では, 焼 結後素材形状を大きく変更するのは困難であるため, 焼結後 に製品形状に近い素材を得るためのネットシェイプ成形技術 の確立が望まれている．セラミックス材は，粉末を圧粉成形 した後焼結することによって製品になるが，セラミックス圧 粉体は焼結中に大きく収縮し, 焼結後の素材形状を予測する ことは一般に困難である.セラミックス製品の生産現場では, 技術者の経験的知識によって加工条件が主に決定されている が, 試行錯誤のための繰返しおよび材料歩留りが問題となつ ている. 最近新しいセラミックス材料が相次いで開発されて いるが，これらの製品化に際しては，技術者の経験的知識だ けでは対処できなくなっており, 焼結後の形状を予測できる 方法が実際の現場において望まれている.

粘塑性有限要素法によって,アルミナ粉末材の突起付きリ ングにおける焼結後の形状予測を試みる. 計算は軸対称変形 としている. Fig.1は突起付きリングの圧粉成形後における断 面の相対密度分布である. 粉末充填時は一様な密度分布であ るが，一体のパンチで圧粉成形を行うと，突起が付いている ため真の圧縮率が突起部とフランジ部で異なり, 圧粉体は密 度分布を有する。相対密度はフランジ部で高く, 突起部で低 くなっている.

Fig.1において求められた圧粉体の密度分布を元にして焼結 収縮の計算を行った。圧粉体の不均一な密度分布によって, 


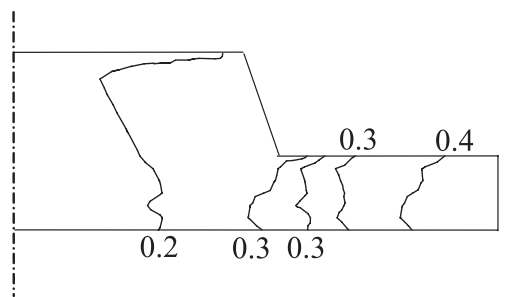

Fig.1 Distribution of calculated relative density in compact of alumina powder formed by single-action press

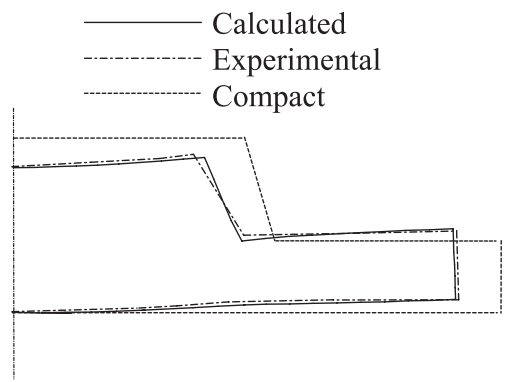

Fig.2 Comparison between shapes of sintered product obtained from calculation and experiment.

焼結中に不均一に収縮する. 突起付きリングの焼結後の形状 をFig.2に示す. 突起部の方が低い相対密度であるため, フラ ンジ部より大きく収縮しており, 焼結後の形状は圧粉体の形 状と相似形にならないで不均一な収縮をしており，焼結体は 曲がりを示しており, 焼結後に大きな仕上げが必要になる.

\section{4 蟒結体のネットシェイプ成形}

密度分布および自重などよって, 焼結体は圧粉体と相似形 状にはならない. 基本的には均一な密度分布の圧粉体を成形 すればよいが, 複雑な形状の製品に対しては成形が困難にな る. そこでシミュレーションにおいて, 焼結後に所定の製品 形状になるように圧粉体の形状を最適化する ${ }^{3)}$. 圧粉体の形 状は, 圧粉金型の形状を変化させることによって達成できる.

先ず，目標とする製品形状に対して圧粉体が均一に収縮す るとして, 圧粉金型の形状を設定する.この圧粉金型で Fig.3 に示すように圧粉および焼結の変形計算を粘塑性有限要素法 によって行い, 焼結後の形状を求める. 目標形状と計算され た形状の差を求め, その差を圧粉金型の形状から引くことに よって新しい金型形状を求める. 得られた圧粉金型で再び圧 粉および燒結の計算を行い, 形状の差を求めて金型形状を修 正する.これを繰返すことによって形状を収束させ，目標と する燒結体の形状を得るための圧粉金型の形状を求める.

アルミナ材の突起付き円板とリングにおいて, 圧粉成形お よび焼結を粘塑性有限要素法によってシミュレーションし， 圧粉金型形状の最適化を行う. 突起部とフランジ部で真の圧 縮率が異なって圧粉体に密度分布が生じ，3 章で示したよう に焼結時に不均一に収縮する. 圧粉金型の形状を最適化させ た計算結果をFig.4に示す.フランジ部の方が突起部の方より

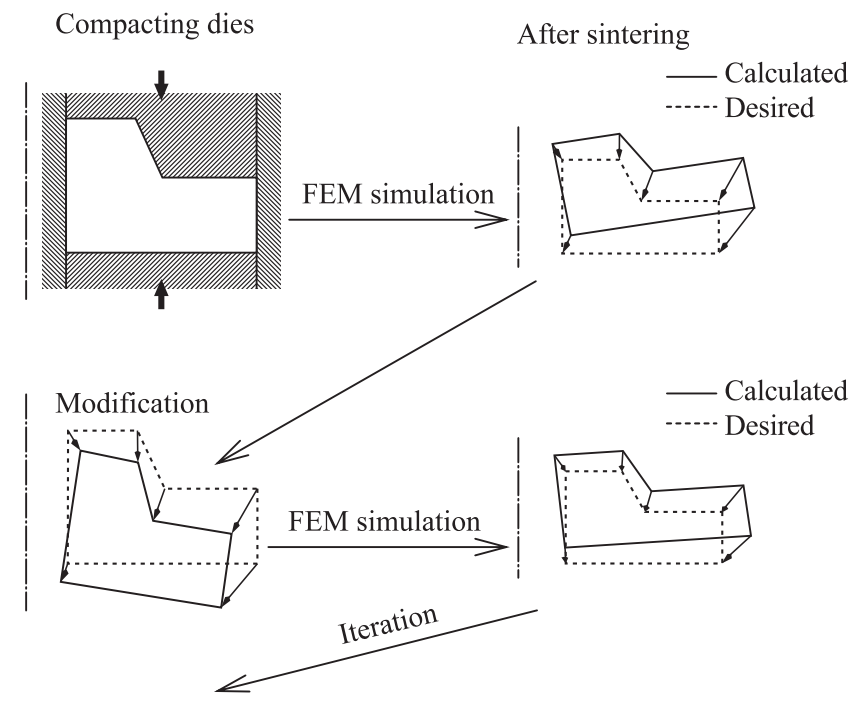

Fig.3 Net-shape approach using finite element simulation for optimisation of compacting dies.

密度が大きくなるため, 1 回目の計算では焼結体と目標形状 とのずれが大きいが, 7 回目の計算で目標形状にほぼ近い結 果が得られている.

シミュレーションで最適化された金型を用いて実験を行い, 得られた焼結体形状と目標形状の比較をFig.5に示す. 最適化 された金型による実験結果は, Fig.4の1回目である最適化さ れていない金型と比較して, 下面の曲りが修正されてほぼ水 平となっており, 目標形状に近づいている. 本解析法は, 粉 末材のネットシェイプ化に対して有効な方法である.

\section{5 焼結割れ発生の予測}

セラミックス压粉体は焼結中に大きく収縮するが, 密度分 布, 自重, 敷板との摩擦などによってその収縮は不均一にな る. 不均一収縮が大きいと割れが生じることがあり，セラ ミックス製品の生産において問題となっている. しかしなが ら，セラミックス圧粉体の燒結時に発生する割れを予測する 試みはまだほとんど行われていない.

焼結過程において, 不均一収縮するときと均一収縮すると きの体積ひずみの差が正の場合には静水圧応力が引張りにな り, 反対に体積ひずみ差が負の場合は圧縮応力になる. 静水 圧応力が引張りの場合は割れが生じる可能性があるため, 焼 結後の製品において均一収縮するときとの体積ひずみ差焼結 割れ発生予測式が提案されている6,7).

$$
\begin{aligned}
& \mathrm{W}= \begin{cases}0 & (\mathrm{R} \leq 0) \\
\mathrm{R} & (0<\mathrm{R} \leq 100), \\
100 & (100<\mathrm{R})\end{cases} \\
& \mathrm{R}=\alpha\left(\rho_{0}\right) \Delta \varepsilon_{\mathrm{v}}+\beta\left(\rho_{0}\right)
\end{aligned}
$$

ここで, $\mathrm{W}(\%)$ は割机確率, $\alpha\left(\rho_{0}\right), \beta\left(\rho_{0}\right)$ は圧粉体の初期相対 密度の関数である. 


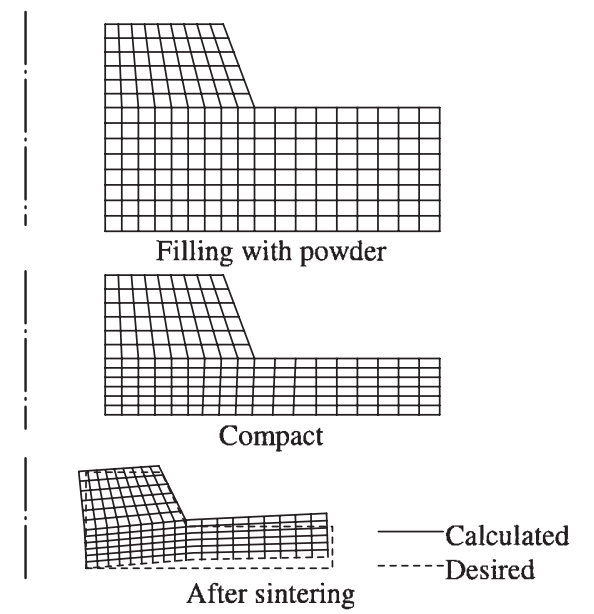

(a) 1st iteraction

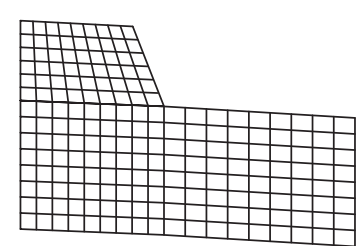

Filling with powder

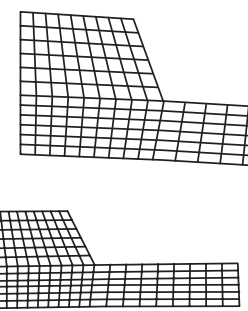

b) 3rd iteraction
Compact

After sintering

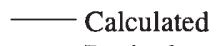

Desired

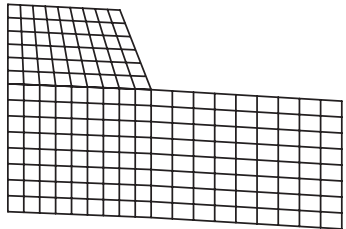

Filling with powder
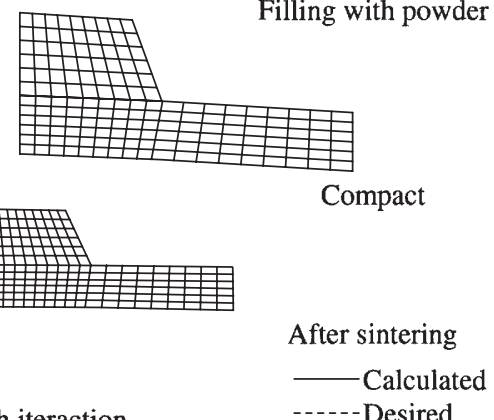

Fig.4 Optimization of shape of compacting dies by net-shape approach.

アルミナの突起付き製品に対して, 割れ発生予測式から求め られた割れ発生率分布と実験結果の比較をFig.5に示す. 割れ る場合と割れない場合があるため, 計算と同じ条件で10数回 実験を行い, 実験の割れ発生率を求めた. 突起付きリングの 実験ではクラックが直接観察されたが, 突起付き円板では発生 したクラックが暁結された痕が下面でほとんどの製品に残って いた. 計算によって得られた割れ発生率および発生位置は実 験結果とよく一致しており, 本予測式が有効であることが分る.

$$
6 \text { マイクローマクロシミュレーション }
$$

有限要素法では，巨視的な情報は得られるが，焼結後の材 質などの微視的情報は求まらない. そこで, Fig.6に示すよう に焼結収縮における粘塑性有限要素法とモンテカルロ法を連

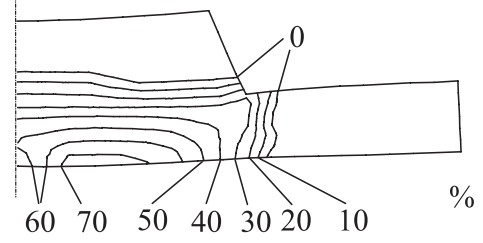

(a) Predicted

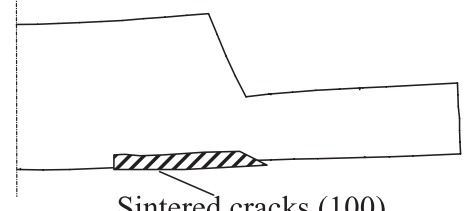

(b) Experimental

Fig.5 Comparison between distributions of fracture rates in sintering obtained by prediction and experiment.

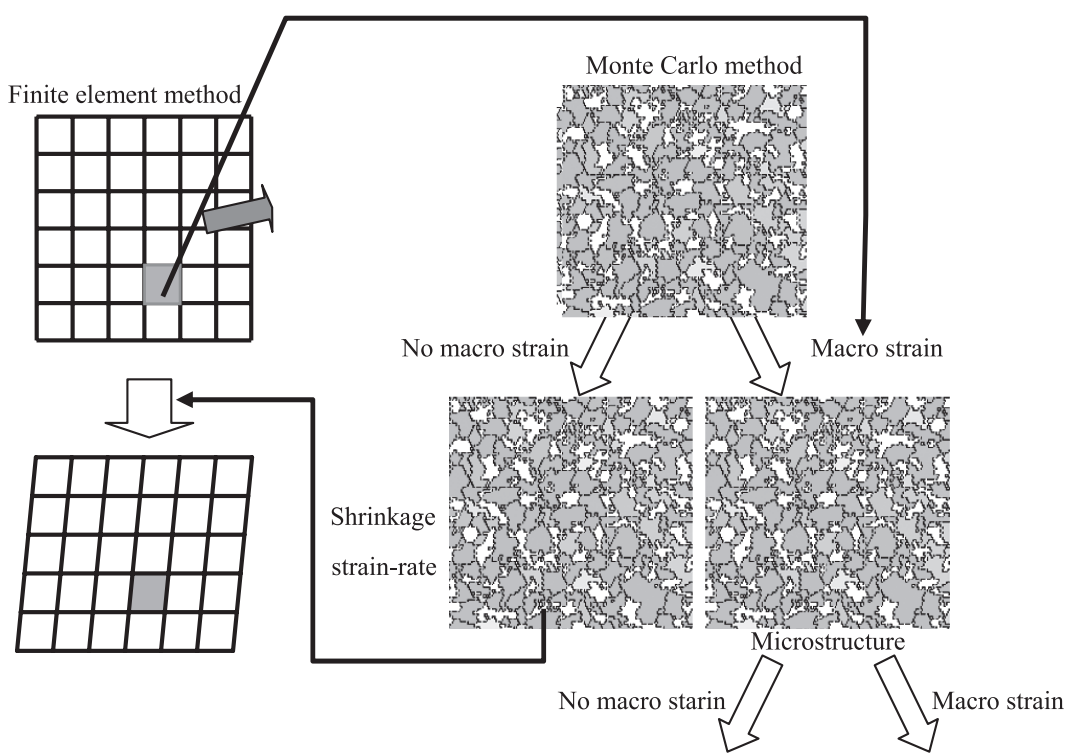

Fig.6 Coupling of Monte Carlo and finite element methods for micro-macro simulation of sintering. 


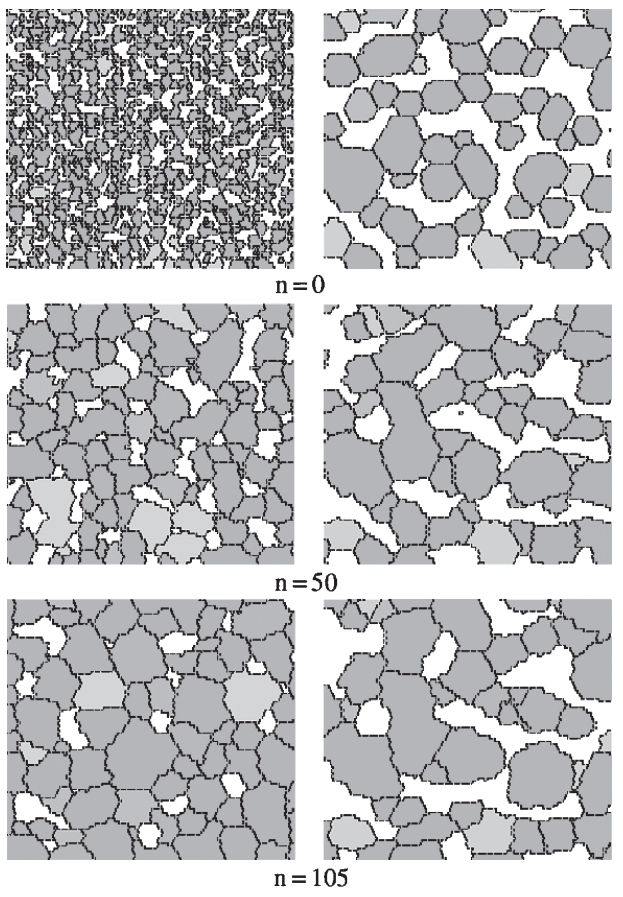

(a) Upper layer

Fig.7 Microstructural change calculated by Monte Carlo method.

成させたマイクローマクロシミュレーションを行った ${ }^{8)}$. 焼 結される圧粉体を多数の要素に分割して有限要素法によって 巨視的変形を計算し，また各要素の中心において微視的な領 域を考えて多数の粉末粒子を配置し，モンテカルロ法によっ て微視的収縮挙動を計算する. 有限要素法とモンテカルロ法 によって得られた情報を焼結中に交換することによって巨視 的と微視的挙動の連成を図る. 有限要素法からモンテカルロ 法に巨視的なひずみ速度を渡し, 逆にモンテカルロ法からは 有限要素法の材料特性である均一収縮ひずみ速度を渡す。

粒径の異なるアルミナ2 層圧粉円板の焼結におけるマイク ローマクロシミュレーションを行い, モンテカルロ法によっ て計算された微視的組織変化の結果をFig.7に示す.圧粉円板 の直径は $25.5 \mathrm{~mm}$, 板厚は $5.6 \mathrm{~mm}$, 相対密度は 0.5 であり, 粒 径だけが異なるため二つの粉末の変形抵抗は等しいとし, $1400^{\circ} \mathrm{C}$ で 1 時間保持している. 上層は平均粒径 3.4 セル, 下

層は平均粒径 $11.5 セ ル$ 粒子であり, 上層と下層の厚さは等し い. 粒径の小さな上層では焼結が速く進み, 焼結初期に緻密 化が進んでいるが, 下層では粒成長は起こっているが気孔の 収縮は大きくない。

\section{7 結 言}

有限要素法は, 生産加工の分野においてはシミュレーショ ンのツールとしての地位を築き上げつつある，このため，粉 末焼結の製造プロセスにおいても有限要素法が同様な効果を もたらすことが期待されている. 有限要素シミュレーション によって加工中の各種の情報が得られると, 従来実験的に行 われてきた試行錯誤の数を減らすことができ, 加工の最適化 が迅速に行えるようになる.

\section{文献}

1) K. Mori, S. Shima, and K. Osakada: "Finite Element Method for the Analysis of Plastic Deformation of Porous Metals", Bull. JSME, 23(1980)516-522.

2) K. Mori and K. Osakada: "Analysis of the Forming Process of Sintered Powder Metals by Rigid-Plastic Finite-Element Method", Int. J. Mech. Sci., 29(1987)229-238.

3) K. Mori: "Finite Element Simulation of Powder Forming and Sintering", Computer Methods in Applied Mechanics and Eng., 195(2006)6737-6749.

4) S. Shima and M. Oyane: "Plasticity Theory for Porous Metals", Int. J. Mech. Sci., 18(1976)285-291.

5) K. Mori, K. Osakada, T. Yoneda, and T. Hirano: "Prediction of Shape of Sintered Ceramic Products by Finite Element Method", J. Japan Soc. Tech. Plasticity, 32(1991)136-1141.

6) K. Mori, K. Osakada, and M. Miyazaki: "Prediction of Fracture in Sintering of Ceramic Powder Compact", Int. J. Machine Tools Manufact., 37(1997)1327-36.

7) K. Mori and K. Osakada: "Net Shape Approach for Sintering Process of Graded Laminated Powder Materials Using Finite Element Simulation", Ann. CIRP, 48(1999)239-242.

8) K. Mori, H. Matsubara, and N. Noguchi: "Micro-Macro Simulation of Sintering Process by Coupling Monte Carlo and Finite Element Methods", Int. J. Mech. Sci., 46(2004)841-854. 